\title{
An Overlapping Generations Model of Growth and the Environment
}

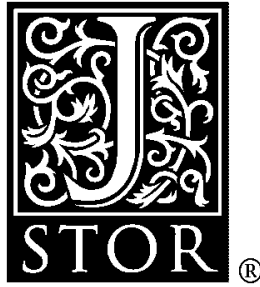

\author{
A. John; R. Pecchenino
}

The Economic Journal, Vol. 104, No. 427. (Nov., 1994), pp. 1393-1410.

Stable URL:

http://links.jstor.org/sici?sici=0013-0133\%28199411\%29104\%3A427\%3C1393\%3AAOGMOG\%3E2.0.CO\%3B2-Y

The Economic Journal is currently published by Royal Economic Society.

Your use of the JSTOR archive indicates your acceptance of JSTOR's Terms and Conditions of Use, available at

http://www.jstor.org/about/terms.html. JSTOR's Terms and Conditions of Use provides, in part, that unless you have obtained prior permission, you may not download an entire issue of a journal or multiple copies of articles, and you may use content in the JSTOR archive only for your personal, non-commercial use.

Please contact the publisher regarding any further use of this work. Publisher contact information may be obtained at http://www.jstor.org/journals/res.html.

Each copy of any part of a JSTOR transmission must contain the same copyright notice that appears on the screen or printed page of such transmission.

JSTOR is an independent not-for-profit organization dedicated to and preserving a digital archive of scholarly journals. For more information regarding JSTOR, please contact support@jstor.org. 
The Economic Journal, ro4 (November), 1393-1410. (C) Royal Economic Society 1994. Published by Blackwell Publishers, 108 Cowley Road, Oxford OX 4 IJF, UK and 238 Main Street, Cambridge, MA 02 142 , USA.

\title{
AN OVERLAPPING GENERATIONS MODEL OF GROWTH AND THE ENVIRONMENT*
}

\section{A. John and R. Pecchenino}

\begin{abstract}
This article analyses the potential conflict between economic growth and the maintenance of environmental quality in an overlapping generations model. Short-lived individuals make decisions which have long-lasting effects on both factor productivity and the environment. The model provides a theoretical explanation of observed correlations between environmental quality and income, whereby economic growth is associated first with declines, then improvements, in environmental quality. It suggests circumstances in which multiple Pareto-ranked steady-state equilibria may arise, and in which sustained growth of both capital and environmental quality may occur. Overmaintenance of the environment, analogous to dynamically inefficient overaccumulation of capital, may emerge.
\end{abstract}

The potential conflict between economic growth and environmental quality was a prominent source of contention at the United Nations Conference on Environment and Development (the 'Earth Summit') in Rio de Janeiro in June I 992. Developed countries, now coming to terms with the environmentally profligate policies of the past, are currently concerned about the long-run effects of global environmental degradation, while developing countries, concerned more with survival than greenery, seek faster growth.

The evidence on possible trade-offs between growth and environmental quality invites careful analysis. Cross-sectional studies by the World Bank suggest that some environmental problems, such as water pollution and sanitation, are most severe at low income levels, while others, such as emission of greenhouse gases, are worst in high income countries (see World Bank (1992), p. I I). Perhaps most interestingly, air pollution (sulphur dioxide, suspended particulate matter, and other pollutants) seems to be worst in middle income countries (see Grossman and Krueger (I99I), Selden and Song (1993), World Bank (1992)). We offer a time-series explanation of these crosssectional findings in a dynamic general equilibrium model. The paper shows how such results can arise when short-lived individuals make decisions concerning the accumulation of capital and the provision of a public good, environmental quality, where these decisions have long-lasting effects.

Environmental issues have been analysed extensively in the environmental and natural resource literatures (see, for example, Baumol and Oates (1988) and Dasgupta and Heal (I979)), but by assuming that the life span of individuals and the life span of the economy are the same (possibly infinite), researchers in environmental economics have for the most part restricted themselves formally to the analysis of intragenerational problems. Further, although intergenerational issues have been extensively discussed in the

* We would like to thank: Steve Durlauf, Donald Hester, Jeff Lacker, Stacey Schreft; seminar participants at Michigan State University, the Federal Reserve Bank of New York, the University of Virginia, and the University of California, Santa Barbara; and two referees for their comments. We take responsibility for all errors. This work is supported in part by NSF grant No. SES 9022825. 
exhaustible resource literature (see, for example, Solow (1974, I986)), they are, for the most part, absent in models of pollution. ${ }^{1}$ Concern with economic growth, meanwhile, is resurgent, as is evidenced by the work of Romer (I 986 ), Lucas (1988), Stokey (1988) and many others. Much of this work emphasises the role of external increasing returns: investment in capital by one agent improves the productive efficiency of all. This 'new growth theory' relies on positive externalities to generate growth, but does not consider how negative externalities from growth might in turn affect the growth process.

The model developed here utilises the overlapping-generations framework of Allais (1947), Samuelson (1958) and Diamond (1965). Such a demographic structure permits analysis of situations where agents' actions have consequences that outlive them. ${ }^{2}$ Agents live two periods, working while young and consuming while old. The young allocate their wages between investment in capital and investment in the environment, a public good. Agents get utility from consumption and environmental quality. Their consumption degrades the environment bequeathed to future generations, but their investment in environmental quality improves the environment bequeathed to future generations. Investment in capital improves the technology available to future generations since the technology exhibits external increasing returns.

Section I of the paper sets out the model and defines equilibrium. Section II characterises interior equilibrium without external increasing returns; Section III considers the corner solution where agents do not engage in maintenance; and Section IV considers equilibrium with external increasing returns. Welfare analysis is contained in Section V. Section VI concludes.

\section{THE ENVIRONMENT}

Consider an infinite-horizon economy comprised of finitely-lived individuals and perfectly competitive firms. A new generation (called generation $t$ ) is born at each date $t=\mathrm{I}, 2, \ldots$, and lives for two periods. Assume no population growth and normalise the size of each generation to unity. ${ }^{3}$ Agents born at date $t$ have preferences defined over consumption in old age, $c_{t+1}$, and an index of the quality of the environment when they consume, $E_{t+1}{ }^{4}$ These preferences are

1 John et al. (1994) consider appropriate tax policies in a model similar to the one utilised in this paper, while John and Pecchenino (I993) analyse both international and intragenerational environmental externalities. Howarth and Norgaard (1990) use a three-period model to consider the impact of property rights on intergenerational equity, while Mäler (1993) considers whether or not the decentralised equilibrium in an overlapping generations economy is optimal when agents have well-defined property rights over nonreproducible environmental resources.

2 The overlapping generations framework is not unknown in the literature on public goods. Kemp and Long (1980) and Mourmouras (r 99I) use it to analyse natural resource use, Mäler (1993) for the pricing of natural resources, and Sandler ( 1982 ) for the optimal provision and maintenance of club goods, such as national parks, in a finite horizon economy.

3 We consider population growth in a similar model in John et al. (1994).

4 A simplifying assumption of our model is that agents do not consume in youth (and do not derive utility from the environment in youth). We adopt this specification for three reasons. First, we wish to focus attention on the choice between investment in the environment and investment in physical capital. The consumption-saving choice is thus secondary to our main concerns. Second, in keeping with most overlapping generations analyses, we wished to keep the model simple by allowing agents to optimise on one margin only. Finally, much of the paper is directed at demonstrating possible outcomes and, in particular, showing that the patterns observed in the data can arise even in a simple and stylised model.

(C) Royal Economic Society 1994 
represented by the utility function $U\left(c_{t+1}, E_{t+1}\right)$. Assume that $U(\cdot)$ is twice continuously differentiable and that $U_{1}\left({ }^{\cdot}\right), U_{2}\left({ }^{\cdot}\right)>0 ; U_{11}\left({ }^{\cdot}\right), U_{22}\left({ }^{\cdot}\right)<0$; and $U_{12}(\cdot) \geqslant 0$. Assume also that $\lim _{c \rightarrow 0} U_{1}(c, E)=\infty .^{5}$

Young agents are each endowed with one unit of labour which they supply to firms inelastically. They divide their wage, $w_{t}$, between saving, $s_{t}$, for consumption when old, and investment in environmental maintenance and improvement, $m_{t}$. When old, agents supply their saving inelastically to firms and earn the gross return $\left(\mathrm{I}+r_{t+1}\right)$.

Environmental quality is a public good that evolves according to ${ }^{6}$

$$
E_{t+1}=(\mathrm{I}-b) E_{t}-\beta c_{t}+\gamma m_{t} ; \quad \beta>0, \gamma>0 .
$$

In the absence of human activity, the quality of the environment has an autonomous level of zero; the parameter $b \in[\mathrm{o}, \mathrm{I}]$ measures the speed of reversion of environmental quality to this level. The term $\beta c_{t}$ is the degradation of the environment as a result of the consumption of the old at $t$, while $\gamma m_{t}$ measures environmental improvement as a result of actions of the young at $t .^{7}$ Possible interpretations of $E_{t}$ include: the quality of soil or groundwater; the cleanliness of rivers and oceans; some index of biodiversity; or the inverse of the atmospheric concentration of chlorofluorocarbons, greenhouse gases, or other pollutants. More broadly, $E_{t}$ could correspond to national parks, which have amenity value and which also require maintenance. ${ }^{8}$

The firms are perfectly competitive profit maximisers who produce output using the production function $Y_{t}=\psi\left(K_{t-1}\right) F\left(K_{t}, N_{t}\right)$. Assume $F()$ exhibits constant returns to scale, so output per worker can be written as $y_{t}=\psi\left(K_{t-1}\right) f\left(k_{t}\right)$, where $k_{t}$ is the capital-labour ratio. Assume $f(0)=0, f^{\prime}(\cdot)>0, f^{\prime \prime}(\cdot) \leqslant 0$, and $k f^{\prime \prime}(\cdot)+f^{\prime}(\cdot)>0$. The function $\psi\left(K_{t-1}\right)$ is a technological externality that captures enhancements to productivity from last period's capital $\left(\psi^{\prime}(\cdot) \geqslant 0\right)$. Because $K_{t-1}$ is predetermined at time $t, \psi\left(K_{t-1}\right)$ is a constant from the perspective of current producers. Thus although the model exhibits increasing returns from an intertemporal social perspective, production at any time period

\footnotetext{
5 We exclude intergenerational altruism, although we do consider the decisions of a long-lived social planner in Section V.

${ }^{6}$ Note that $E$ is therefore simply an index of the amenity value of environmental quality that can take on positive or negative values. In particular, no special significance attaches to $U(\cdot, 0)$. In a more specific setting, we might wish to associate $E$ with some particular biophysical index, in which case we would place appropriate restrictions on preferences and technologies.

7 Our model differs from Mäler (1993) in that we assume that environmental quality is a public good that is affected by consumption externalities and that enters the utility function, while he assumes that property rights can be assigned over environmental resources that enter the production function. In Mäler's model, the existence of property rights allows environmental resources to be efficiently priced even though agents are short-lived. In our model, the absence of property rights implies that environmental quality may not be dynamically efficient even though agents value the environment and contribute to its maintenance. See Section $\mathrm{V}$ below.

${ }^{8}$ For some environmental problems, such as ozone layer depletion or biodiversity loss, direct amelioration of the environment is difficult or impossible. We could however interpret $m_{t}$ as pollution abatement, and think of the equation in the text as a linear approximation of a more complicated relationship among consumption, abatement, and the quality of the environment. Evidently, also, some environmental problems are longer-lived than others. Note, though, that even short-lived environmental externalities can have longlived consequences. For example, if acid rain damages an ancient monument, its effects remain after the pollution problem is solved. Similarly, ocean or river pollution could have effects on fish stocks that persist long after the resource is cleaned up.
} 
is a constant-returns activity. ${ }^{9}$ Since the population is normalised to one, $\psi\left(K_{t-1}\right)$ can be written as $\psi\left(k_{t-1}\right)$. The capital stock depreciates at rate $\delta \in[\mathrm{o}, \mathrm{I}]$.

Because our focus is on external effects across generations, we wish to abstract from the well-understood free-rider problems within a generation. We therefore assume that those alive at date $t$ are represented by a one-period lived government whose sole responsibility is the provision of the public good, environmental quality, for the benefit of agents alive during its period of office. Specifically, it levies lump-sum taxes on the young to achieve their jointly desired level of environmental maintenance, while leaving the welfare of the old unchanged. Equivalently, we can think of a social planner's setting prices for the public good such that agents will fund it at the socially optimal level for that generation. This is, essentially, the pricing mechanism underlying a Lindahl equilibrium.

Agents take as given the wage, $w_{t}$, the return on saving, $r_{t+1}$, and environmental quality at the beginning of period $t, E_{t} \cdot{ }^{10}$ The lifetime choice problem of a representative agent is to choose $c_{t+1}, m_{t}$ and $s_{t}$ to maximise

subject to

$$
U\left(c_{t+1}, E_{t+1}\right)
$$

$$
\begin{gathered}
w_{t}=s_{t}+m_{t} \\
c_{t+1}=\left(\mathrm{I}+r_{t+1}\right) s_{t} \\
E_{t+1}=(\mathrm{I}-b) E_{t}-\beta c_{t}+\gamma m_{t} \\
c_{t+1}, m_{t}, s_{t} \geqslant 0 .
\end{gathered}
$$

The individual firm takes the wage and the rental rate on capital as given. It hires labour until the marginal product of labour equals the wage, and hires capital until the net marginal product of capital equals the rental rate. ${ }^{11}$

A competitive equilibrium for this economy is a sequence $\left\{k_{t}, c_{t}, w_{t}, r_{t}, m_{t}, s_{t}\right.$, $\left.E_{t}\right\}_{1}^{\infty}$, such that, at each date $t=\mathrm{I}, 2, \ldots$,

(i) agents maximise (I) subject to (2)-(4);

(ii) firms maximise profits;

(iii) markets clear;

and $\left\{k_{1}, E_{1}\right\}$ are given.

9 The inclusion of last period's capital stock in the current production technology is motivated by the recent literature on external increasing returns in growth models; see, for example, Romer (1986) and Weil (1989). Romer's insight, drawing on Arrow's (1962) analysis of learning-by-doing and Young's (1928) analysis of increasing returns, is that production generates knowledge as a by-product.

${ }^{10}$ In this problem, we make the competitive assumption that the return on saving is taken as given. Alternatively, we could analyse a planner's problem in which the planner takes account of the fact that the allocation of output to maintenance or saving affects the return to saving. The only difference between the two approaches is that the latter includes an extra term in the return to saving in the first-order condition, (7); the main conclusions of the paper are unaffected. We choose our formulation for a number of reasons. First, we wish to stay as close as possible to the Diamond (1965) model. Second, the planning approach complicates matters by effectively introducing an extra distortion, since young agents no longer act as pricetakers. Third, we analyse the effect of that distortion elsewhere; see John et al. (1994).

${ }^{11}$ We also assume that there is an initial generation of old agents who are endowed with the capital stock in the first period $\left(k_{1}\right)$. These old agents supply their capital to firms and consume the proceeds $\left(c_{1}=\left(\mathrm{I}+r_{1}\right) k_{1}\right)$. The firms in the first period are endowed with the technology $\psi\left(k_{0}\right) f\left(k_{1}\right)$, where $\psi\left(k_{0}\right)$ is given. 
II. INTERIOR EQUILIBRIUM WITHOUT EXTERNAL INGREASING RETURNS

We first analyse equilibrium in the absence of external increasing returns. That is, we set $\psi(k)=\mathrm{I}$, all $k$. Along a dynamic equilibrium path, equations (2)-(4) and the following equations $((5)-(8))$ are satisfied for all $t$ :

$$
\begin{gathered}
r_{t}=f^{\prime}\left(k_{t}\right)-\delta=r\left(k_{t}\right) \\
w_{t}=f\left(k_{t}\right)-k_{t} f^{\prime}\left(k_{t}\right)=w\left(k_{t}\right) \\
U_{1}\left(c_{t+1}, E_{t+1}\right)\left(\mathrm{I}+r_{t+1}\right)-\gamma U_{2}\left(c_{t+1}, E_{t+1}\right)=\mathrm{o} \\
k_{t+1}=s_{t} .
\end{gathered}
$$

Equations (5) and (6) are the standard first-order conditions from the firm's maximisation problem in period $t$. Equation (7) is the first-order condition from the agent's maximisation problem: the individual chooses $s_{t}$ to equate the marginal rate of substitution between consumption and environmental quality to the marginal rate of transformation. ${ }^{12}$ This presumes an interior solution, although nothing in the model precludes the possibility that agents choose not to engage in maintenance; we consider this possiblity in the next section. Equation (8) is the goods market clearing condition: the capital stock at $t$ is fully determined by saving decisions made at $t-\mathrm{I}$.

The dynamic behaviour of the system can be determined as follows. Leading (5) one period and substituting out for $s_{t}, r_{t+1}, w_{t}$ and $m_{t}$ yields

$$
\begin{gathered}
c_{t+1}=(\mathrm{I}-\delta) k_{t+1}+\nu\left(k_{t+1}\right) f\left(k_{t+1}\right)=c\left(k_{t+1}\right) \\
U_{1}\left(c_{t+1}, E_{t+1}\right)\left[\mathrm{I}+f^{\prime}\left(k_{t+1}\right)-\delta\right]-\gamma U_{2}\left(c_{t+1}, E_{t+1}\right)=0 ; \\
E_{t+1}=(\mathrm{I}-b) E_{t}-\beta c_{t}+\gamma\left\{\left[\mathrm{I}-\nu\left(k_{t}\right)\right] f\left(k_{t}\right)-k_{t+1}\right\} ;
\end{gathered}
$$

where $\nu(k)=k f^{\prime}(k) / f(k)$ is capital's share of output. Now use (9) and (9) lagged one period to rewrite (Io) and (I I) as

$$
\begin{gathered}
U_{1}\left[c\left(k_{t+1}\right), E_{t+1}\right]\left[\mathrm{I}+r\left(k_{t+1}\right)\right]-\gamma U_{2}\left[c\left(k_{t+1}\right), E_{t+1}\right]=0 ; \\
E_{t+1}=(\mathrm{I}-b) E_{t}-\beta c\left(k_{t}\right)+\gamma\left\{\left[\mathrm{I}-\nu\left(k_{t}\right)\right] f\left(k_{t}\right)-k_{t+1}\right\} . \\
\quad=(\mathrm{I}-b) E_{t}-\beta(\mathrm{I}-\delta) k_{t}+\rho\left(k_{t}\right) f\left(k_{t}\right)-\gamma k_{t+1} ;
\end{gathered}
$$

where $\rho\left(k_{t}\right)=\left\{\gamma\left[\mathrm{I}-\nu\left(k_{t}\right)\right]-\beta \nu\left(k_{t}\right)\right\}$. Since (12) implicitly defines $E_{t+1}$ as a function of $k_{t+1}$ only, rewrite it as

$$
E_{t+1}=\phi\left(k_{t+1}\right) \text {. }
$$

It is easy to confirm that $\phi^{\prime}()>0$ : agents choose their mix of saving and maintenance such that a higher capital stock is associated with higher environmental quality. ${ }^{13}$ Finally, substitute (I4) and (I4) lagged once into (I3) to obtain the following first-order nonlinear difference equation in $k$ :

$$
\phi\left(k_{t+1}\right)+\gamma k_{t+1}-(\mathrm{I}-b) \phi\left(k_{t}\right)+\beta(\mathrm{I}-\delta) k_{t}-\rho\left(k_{t}\right) f\left(k_{t}\right)=\mathrm{o} .
$$

12 The Samuelson condition for the optimal provision of a public good (the marginal rate of transformation equals the sum of agents' marginal rates of substitution) is trivially satisfied in equation (7), since the number of agents has been normalised to one. The condition is only satisfied for a single generation, however; the dynamic analog of this condition appears in Section IV below.

${ }^{13}$ Specifically, $\phi^{\prime}()=-\left[U_{11} c^{\prime}(\mathrm{I}+r)+U_{1} r^{\prime}-\gamma U_{12} c^{\prime}\right] /\left[U_{12}(\mathrm{I}+r)-\gamma U_{22}\right]$. The assumption that $f^{\prime \prime}(k) k+f^{\prime}(k)>0$ is sufficient (not necessary) for $c^{\prime}()>0$, which, together with our assumption that $U_{12}() \geqslant 0$, is sufficient (not necessary) for $\phi^{\prime}()>0$.

(C) Royal Economic Society 1994 
(a)

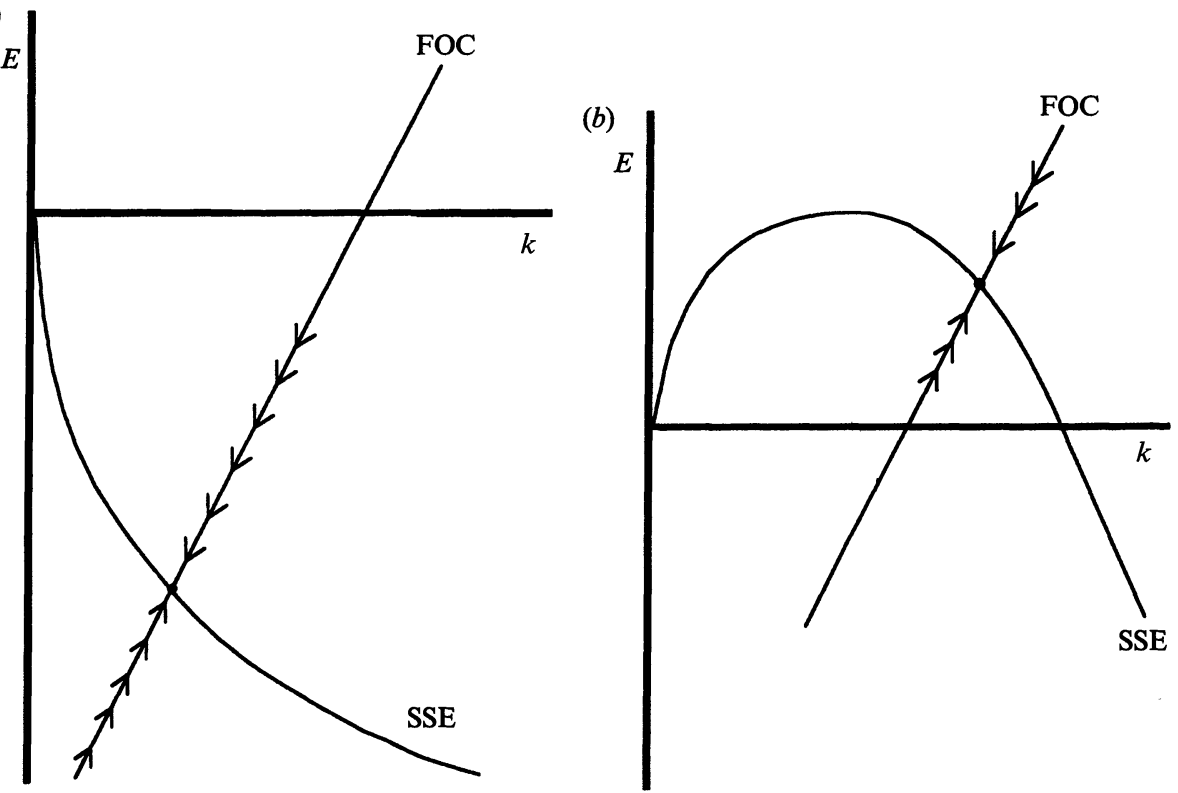

Fig. I. Interior equilibrium without external increasing returns $(a)(\rho<0),(b)(\rho>0)$.

Using ( I 5), we can determine the dynamic behaviour of the capital stock, and hence all other endogenous variables, along an equilibrium path. ${ }^{14}$

We illustrate the economy in $E-k$ space by considering (I3) and (14) separately. Let $\bar{k}$ and $\bar{E}$ denote steady state values. The law of motion for the environment (I3), in steady state, can be rewritten as ${ }^{15}$

$$
\bar{E}=\left(\frac{\mathrm{I}}{b}\right)\{\rho(\bar{k}) f(\bar{k})-[\beta(\mathrm{I}-\delta)+\gamma] \bar{k}\}=\varphi(\bar{k}) . \quad[\mathrm{SSE}]
$$

The first-order condition (I4) is, in steady state,

$$
\bar{E}=\phi(\bar{k}) . \quad[\mathrm{FOC}]
$$

These equations are illustrated in Figs. I $a$ and I $b$. Fig. I $a$ shows the case where $\rho(k)<\mathrm{o} \forall k$; Fig. I $b$ shows the case where $\rho(k)>\circ \forall k .^{16}$ The economy is in steady state where $\phi(\bar{k})=\varphi(\bar{k})$, that is, where the two functions intersect. A

14 The proviso that (I5) holds only along an equilibrium path is important. In particular, note that we used the first-order conditions for both $t-1$ and $t$ in deriving ( 15 ). In effect, ( 15 ) uses the period $t$ equilibrium conditions to obtain $k_{t+1}$, given $k_{t}$ and given that the economy was at an interior equilibrium in period $t-1$.

15 We assume in this and the following discussion that $b>0$. Analysis of the case where $b=0$ is straightforward. The term $\rho(k) f(k)$ is the change in environmental quality that would result if, counterfactually, young agents devoted their entire wage to maintenance: in this case, labour's share of output, [ $1-\nu()] f()$, would go toward maintenance and capital's share, $v() f($ ), would to to consumption. The other two terms reflect the fact that agents do not devote their entire wage to maintenance: each unit of saving by young agents implies both $(1-\delta)$ extra units of consumption and one less unit of maintenance: net environmental improvement each period thus equals $\rho(k) f(k)-[\beta(1-\delta)+\gamma] k$, which must equal the natural decline of environmental quality $(b E)$ in steady-state equilibrium.

${ }_{16}$ If the technology is Cobb-Douglas, then $\nu(k)$ and hence $\rho(k)$ are constant. In this case, Figs I $a$ and I $b$ illustrate the only possible forms of $\varphi(k)$. For other technologies, $\rho(k)$ may change sign as $k$ varies, and $\varphi(k)$ need not be so well behaved. 
steady-state is stable if the FOC line cuts the SSE line from below. We can confirm this by linearising (I5) around steady state to obtain

$$
\left(k_{t+1}-\bar{k}\right)=\left[\frac{(\mathrm{I}-b) \phi^{\prime}-\beta(\mathrm{I}-\delta)+\rho^{\prime} f+f^{\prime} \rho}{\phi^{\prime}+\gamma}\right]\left(k_{t}-\bar{k}\right) .
$$

The coefficient in (18) is less than one if and only if $\varphi^{\prime}(\bar{k})<\phi^{\prime}(\bar{k})$.

There is no (non-autarkic) steady state if the FOC line lies everywhere above the SSE line, and there are two steady-state equilibria if the two curves intersect twice. In this case the equilibrium with higher capital and environmental quality is stable. ${ }^{17}$ Multiple equilibria are consistent with observations of relatively poor economies with serious problems of coincident environmental degradation and economic decline; many countries in Eastern Europe currently fit this description. Contrary to the popular perception that pollution stems from high GDP, it may rather be the case that only rich countries can spare the resources to combat environmental problems. ${ }^{18}$ Such a view was expressed by delegates from developing nations at the Earth Summit.

The dynamic adjustment of the economy is also illustrated in Figs. I $a$ and $\mathrm{I} b$. Because $E_{t}=\phi\left(k_{t}\right)$ in all time periods, the economy adjusts along the FOC. When the equilibrium path of the economy lies below the SSE line, the economy is growing, environmental quality is improving, and the welfare of successive generations is increasing through time.

\section{ZERO-MAINTENANGE EQUILIBRIUM}

Agents in economies with little capital or with high environmental quality may choose not to engage in maintenance of the environment. Maintaining our assumption of no external increasing returns, equilibrium in this case is described by a similar set of equations to before, except that the first-order condition (7) is replaced by the zero-maintenance condition:

$$
m_{t}=o \text {. }
$$

Under zero maintenance, workers save all their wage income, so the evolution of the economy is described by

$$
\begin{gathered}
k_{t+1}=\left[\mathrm{I}-\nu\left(k_{t}\right)\right] f\left(k_{t}\right) ; \\
E_{t+1}=(\mathrm{I}-b) E_{t}-\beta c\left(k_{t}\right) .
\end{gathered}
$$

Zero maintenance is a corner solution to the agent's maximisation problem. Since agents' saving is limited by their wage income, $k_{t+1}$ cannot exceed $w_{t}$. Agents who, if unconstrained, would like to save in excess of their wage are at the corner and carry out no maintenance. We define the zero maintenance

\footnotetext{
17 As noted in footnote 12, the SSE might be less well-behaved than those illustrated in Fig. I, in which case more than two equilibria are possible.

18 The intuition behind the multiplicity is as follows. At a low- $k$, low- $E$ equilibrium, agents have relatively more of an incentive to engage in environmental maintenance. Since agents are putting resources into maintenance, they do not save much and the capital stock is low; this implies that agents have low income and so cannot engage in much maintenance, validating the poor environmental quality. By contrast, at a high- $k$, high- $E$ equilibrium, agents have a greater incentive to save, leading to a higher capital stock and a greater ability to engage in maintenance. Environmental quality is then high, despite the adverse effects of high consumption.
}

(C) Royal Economic Society r 994 
manifold (ZMM) as the set of points where agents are just indifferent between zero and positive maintenance: that is, $\left\{E_{t}, k_{t}\right\}$ such that equations $(2)-(8)$ and (I9) hold. ${ }^{19}$

A zero-maintenance steady-state is defined by

$$
\bar{k}_{z}=w\left(\bar{k}_{z}\right)
$$

and, as before, $E=\varphi(k)$, so that

$$
\bar{E}_{z}=\varphi\left(\bar{k}_{z}\right)=\left(\frac{\mathrm{I}}{b}\right)\left\{\rho\left(\bar{k}_{z}\right) f\left(\bar{k}_{z}\right)-[\beta(\mathrm{I}-\delta)-\gamma] \bar{k}_{z}\right\} .
$$

Equilibrium is illustrated in Fig. 2, which reproduces the steady-state firstorder condition (FOG) and the steady-state environment condition (SSE) from Fig. I $b$, and also shows the zero-maintenance manifold $(\mathrm{ZMM}){ }^{20}$ In the region above the manifold, environmental quality is sufficiently good and/or there is sufficiently little capital that agents choose not to engage in maintenance. Fig. 2 also shows the loci of points such that the capital stock is

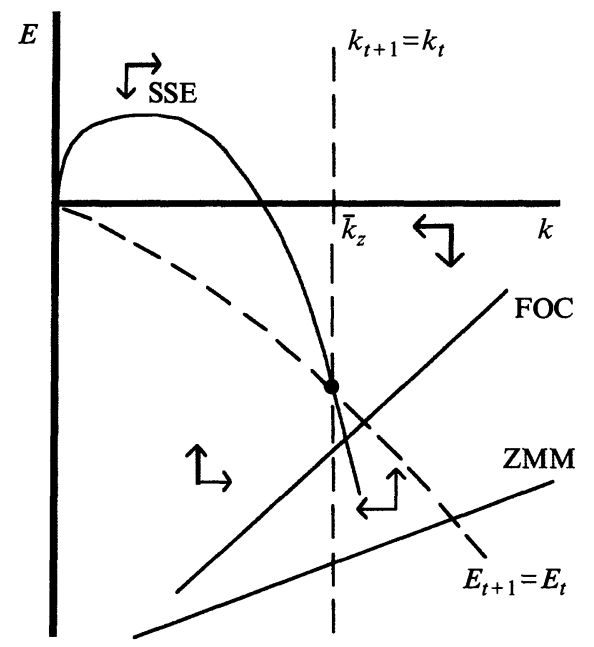

Fig. 2. Dynamic adjustment to zero-maintenance steady state.

unchanging (given by $k=\bar{k}_{z}$ ) and such that environmental quality is unchanging (given by $E=-(\beta / b) c(k)$ ). Above the ZMM line, the adjustment to steady state is indicated by the arrows in the usual way; below the ZMM line the economy is governed by the dynamics derived in the previous section. ${ }^{21}$

19 The general equation of the ZMM is

$$
U_{1}\left\{c\left[w\left(k_{t}\right)\right],(\mathrm{I}-b) E_{t}-\beta c\left(k_{t}\right)\right\}\left\{\mathrm{I}+f^{\prime}\left[w\left(k_{t}\right)\right]-\delta\right\}-\gamma U_{2}\left\{c\left[w\left(k_{t}\right)\right],(\mathrm{I}-b) E_{t}-\beta c\left(k_{t}\right)\right\}=0 .
$$

It is easy to show that the ZMM slopes upward in $E-k$ space.

${ }^{20}$ If we set $k=\bar{k}_{z}$ and find the values of $E$ implied by each relationship, we can show that $\phi\left(\bar{k}_{z}\right)=(\mathrm{I}-b) \bar{E}_{z m m}+b \varphi\left(\bar{k}_{z}\right)$. It follows that the FOC must lie between the SSE and the ZMM at $k_{z}$, as illustrated. Note also that the picture is substantively identical for the case where $\rho(k)<0, \forall k$.

${ }^{21}$ For simplicity, we have analysed the dynamics separately under zero maintenance and at an interior solution. An economy might however move in and out of zero maintenance. To track the behaviour of our model completely, one should check at each date whether the economy lies above or below the ZMM, and then apply the appropriate set of difference equations.

(C) Royal Economic Society 1994 


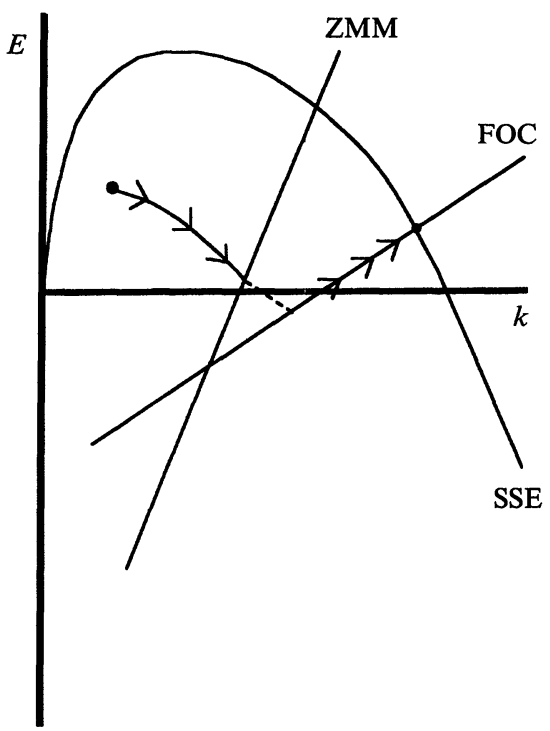

Fig. 3. Initial decline and subsequent improvement in environmental quality.

Now consider an economy that initially possesses little capital and has environmental quality in the neighbourhood of $E=0$. The dynamic adjustment of the economy entails increases in $k$ and decrease in $E$. As agents accumulate capital, the consumption externality causes degradation of the environment; successive generations, being at the zero-maintenance corner, do not find maintenance worthwhile. The dynamics of the economy therefore imply a negative correlation between environmental quality and growth under zero maintenance, in contrast to the positive correlation at interior equilibrium. ${ }^{22}$ Moreover, a growing economy that moves from zero to positive maintenance will exhibit environmental quality that deteriorates initially and later improves. Such adjustment is illustrated in Fig. 3. As noted previously, similar patterns have been observed in cross-sectional data.

The analysis also sheds light on why some environmental problems exhibit improvement at low income levels while others worsen even in rich countries. For problems such as poor water quality, it is likely that the returns to maintenance are high and that agents would be willing to give up large amounts of consumption in return for improvements in environmental quality. In this case, the $\mathrm{ZMM}$ will lie close to the $E$ axis, implying that economies would move into positive maintenance at relatively low values of $k{ }^{23}$ For, say, carbon dioxide build-up, by contrast, the returns to maintenance may be low and agents may value environmental quality relatively less. In this case, the

\footnotetext{
22 As is evident from Fig. 2, it is possible for a growing economy to exhibit improving environmental quality under zero maintenance only if the economy initially suffers from a degraded environment, so that the natural reversion of the environment to its autonomous level outweighs the consumption externality.

${ }^{23}$ It is easy to verify that increases in $\gamma$ shift the ZMM inward. The second assertion is easily proved graphically by representing preferences by indifference curves in $E-k$ space and considering a global change in the marginal rate of substitution.
}

C Royal Economic Society I 994 
ZMM will lie further to the right, implying that even relatively rich economies might continue with zero maintenance. Of course, such results are only suggestive and should more properly be analysed in a model that explicitly includes a number of different environmental concerns.

If the dynamic path of the economy lies under the SSE locus, the utility of successive generations is still increasing along a zero-maintenance growth path, even though environmental quality is deteriorating. ${ }^{24}$ If the path lies above the SSE locus, welfare could be improving or declining, depending on initial conditions. The model can thus generate the phenomenon of economic growth that is more than offset by declining environmental quality: higher income does not automatically translate into higher welfare in the model. ${ }^{25}$

\section{EQUILIBRIUM WITH EXTERNAL INGREASING RETURNS}

Economic growth is usually defined in terms of increased output of goods and services. Environmentalists and others have challenged this definition, noting that increased output won at the expense of a degraded environment need not imply improved social welfare. As just noted, our model can deliver dynamic paths along which the economy is growing but the welfare of successive generations is falling. In this section we modify our model to allow for sustained output growth, and examine the robustness of our previous results.

When current productivity is affected by the last period's capital stock, the interest rate, the wage and the level of consumption are functions of current and lagged capital. That is, equations (5), (6) and (3) are replaced by

$$
\begin{gathered}
r_{t+1}=\psi\left(k_{t}\right) f^{\prime}\left(k_{t+1}\right)-\delta=r\left(k_{t+1}, k_{t}\right) \\
w_{t}=\psi\left(k_{t-1}\right) f\left(k_{t}\right)-k_{t} \psi\left(k_{t-1}\right) f^{\prime}\left(k_{t}\right)=w\left(k_{t}, k_{t-1}\right) \\
c_{t+1}=\left(\mathrm{I}+r_{t+1}\right) k_{t+1}=c\left(k_{t+1}, k_{t}\right) .
\end{gathered}
$$

Interior equilibrium is described by these equations and equations $(2),(4),(7)$ and $(8)$ as before. We can describe equilibrium in this case by ${ }^{26}$

$$
\begin{gathered}
E_{t+1}=\phi\left(k_{t+1}, k_{t}\right) ; \\
E_{t+1}=(\mathrm{I}-b) E_{t}-\beta(\mathrm{I}-\delta) k_{t}+\rho\left(k_{t}\right) \psi\left(k_{t-1}\right) f\left(k_{t}\right)-\gamma k_{t+1} .
\end{gathered}
$$

Along an equilibrium path, the dynamics are described by the following second-order difference equation, which is a natural extension of (18).

$$
\phi\left(k_{t+1}, k_{t}\right)+\gamma k_{t+1}-(\mathrm{I}-b) \phi\left(k_{t}, k_{t-1}\right)+\beta(\mathrm{I}-\delta) k_{t}-\rho\left(k_{t}\right) \psi\left(k_{t-1}\right) f\left(k_{t}\right)=\mathrm{o} .
$$

24 To derive the welfare result we need simply note that, if agents inherit an $\left\{E_{t}, k_{t}\right\}$ pair below the SSE, then they can choose $E_{t+1}>E_{t}$ and $k_{t+1}>k_{t}$. In effect, their budget set contains the point that they inherit.

25 To confirm that declining welfare is possible, consider an economy that initially has $E=o$ and $k=\bar{k}_{z}$. The dynamic adjustment of the economy would entail declining environmental quality and no changes in the capital stock. Welfare would thus be decreasing through time. It is easy to construct less extreme examples.

${ }^{26}$ Note that capital's share is independent of $k_{t-1}$, being given by

$$
k_{t} \psi\left(k_{t-1}\right) f^{\prime}\left(k_{t}\right) / \psi\left(k_{t-1}\right) f\left(k_{t}\right)=k_{t} f^{\prime}\left(k_{t}\right) / f\left(k_{t}\right)=v\left(k_{t}\right)
$$

hence the definition of $\rho(k)$ is unchanged.

(C) Royal Economic Society 1994 
Steady state is defined by

$$
\begin{gathered}
\bar{E}=\phi(\bar{k}, \bar{k}) \\
\bar{E}=\left(\frac{\mathrm{I}}{b}\right)\{\rho(\bar{k}) \psi(\bar{k}) f(\bar{k})-[\beta(\mathrm{I}-\delta)+\gamma] \bar{k}\}=\tilde{\varphi}(\bar{k}) .
\end{gathered}
$$

We know that $\phi_{1}()>0$ and, under weak restrictions, $\phi_{2}()>0$ also, so $\phi(k, k)$ is increasing in $k .{ }^{27}$ Equation (3I) is a simple extension of ( $\left.\mathrm{I} 7\right)$. If the external increasing returns are not too strong, then the qualitative behaviour of the model is little changed, but with strong increasing returns, sustained growth is possible. To show this, we characterise the behaviour of $\tilde{\varphi}$ as $k \rightarrow \infty$.

Lemma I. In what follows, all limits refer to $k \rightarrow \infty$. Let $\lim [f(k) \psi(k) / k]=A$, possibly infinite. Let $\lim \nu(k)=\hat{\nu}$. If $\lim \rho(k)=\gamma(\mathrm{I}-\hat{\nu})-\beta \hat{\nu}>0$ and $A>$ $\frac{\beta(\mathrm{I}-\delta)+\gamma}{\gamma(\mathrm{I}-\hat{v})-\beta \hat{v}}$, then $\lim \tilde{\varphi}(k)=\infty ;$ otherwise $\lim \tilde{\varphi}(k)=-\infty$.

Proof.

$$
\begin{aligned}
\lim \tilde{\varphi}(k) & =\left(\frac{\mathrm{I}}{b}\right) \lim \{\rho(k) \psi(k) f(k)-[\beta(\mathrm{I}-\delta)+\gamma] k\} \\
& =\left(\frac{\mathrm{I}}{b}\right) \lim k\{\rho(k) \psi(k) f(k) / k-[\beta(\mathrm{I}-\delta)+\gamma]\} \\
& =\left(\frac{\mathrm{I}}{b}\right)(\lim k)\{\lim \rho(k) \psi(k) f(k) / k-[\beta(\mathbf{I}-\delta)+\gamma]\} \\
& =\left(\frac{\mathbf{I}}{b}\right)(\lim k)\{[\gamma(\mathrm{I}-\hat{\nu})-\beta \hat{\nu}] A-[\beta(\mathbf{I}-\delta)+\gamma]\}
\end{aligned}
$$

Under the inequalities stated, the term in parentheses is positive; otherwise it is negative. We can note as a corollary that $\lim f^{\prime}(k)=0$ is necessary for $\lim \tilde{\varphi}()=\infty$, because $\lim f^{\prime}(k) \neq 0 \Rightarrow \hat{\nu}=\mathbf{I}$.

If $\psi(k) f(k)$ is strictly concave in $k$, then the qualitative behaviour of the model is substantively identical to Figs. I $a$ and $\mathrm{I} b$. The only difference is that $\phi()$ is a function of two arguments and can now only be used to bound $E_{t+1}$, given values of $k_{t}$ and $k_{t+1}$ : if $k_{t+1}>k_{t}$, then $\phi\left(k_{t+1}, k_{t+1}\right)>E_{t+1}>\phi\left(k_{t}, k_{t}\right)$. If the external increasing returns are sufficiently strong, however, so that $\psi(k) f(k)$ is convex, then the model is as illustrated in Figs. $4 a$ and $4 b^{28}$ Sustained growth is then possible. ${ }^{29}$

27 A sufficient (not necessary) condition for $\phi_{2}()>0$ is $\left[\mathrm{I}+r+U_{11} c / U_{1}\right]>0$.

28 Again, we have drawn the Figures for $\rho(k)<\circ \forall k$ and $\rho(k)>\circ \forall k$; more complicated pictures are possible if $\rho($ ) changes sign.

${ }^{29}$ For sustained growth to occur, we also need $\lim \left[\phi_{1}()+\phi_{2}()\right]>\lim \varphi^{\prime}(k)$. We cannot say much about this condition in general, but it is easy to construct examples where it is satisfied. Our intention in this paper is not to present a model of growth per se, but to examine how capital accumulation and accumulation of environmental quality interact. We have therefore chosen a simple means of generating sustained growth in our model, but we emphasise that the main conclusions of this paper do not rest on an assumption of global increasing returns.

(C) Royal Economic Society 1994 
(a)

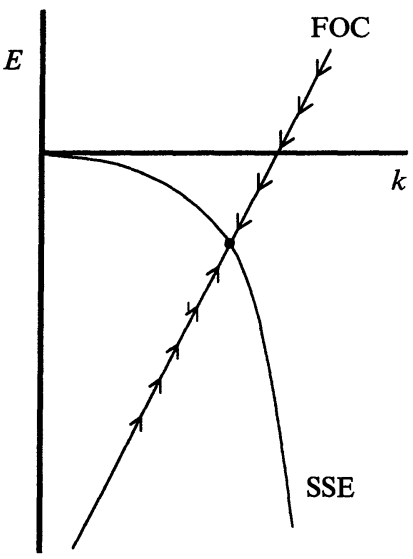

(b)

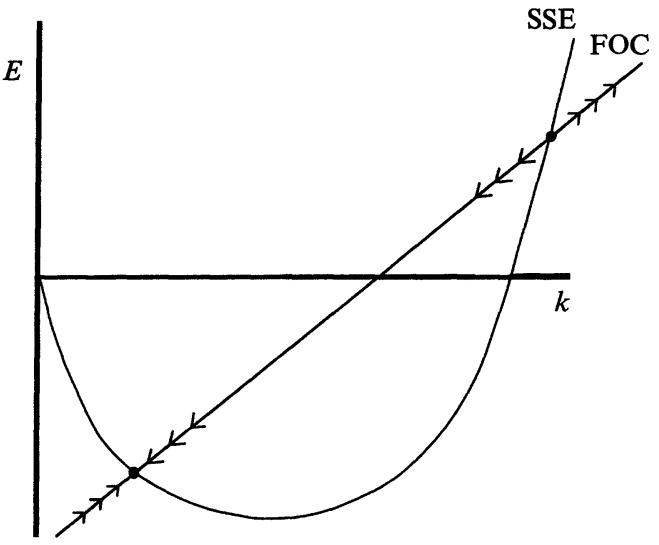

Fig. 4. Interior equilibrium with external increasing returns $(a)(\rho<0),(b)(\rho>0)$.

The model can exhibit a low-level equilibrium trap, as also illustrated in Fig. $4 b$ : economies with sufficient capital and environmental quality can take advantage of the increasing returns and experience sustained growth, while economies with worse initial conditions will move either towards shutdown or a low-level stable equilibrium. A distinctive feature of the model is that we can obtain a stable, non-autarkic, low-level equilibrium, even if the production function exhibits increasing returns throughout. This contrasts, for example, with Azariadis and Drazen (1990), who generate a low-level equilibrium from a discontinuity in the production function, and with Jones and Manuelli (i992), who do not have a stable non-autarkic equilibrium under external increasing returns. In common with those models, however, we confirm that external increasing returns play an important role in the growth process. Jones and Manuelli show that concave production functions preclude growth in a one-sector overlapping generations model because the ratio of wages to the capital stock falls as the capital stock increases, so the young cannot continually purchase larger and larger stocks of capital. In our notation, $A>\mathrm{I} /(\mathrm{I}-\hat{v})$ is therefore necessary for growth, but we require a stronger restriction because, in our setting, richer economies must also devote more income to environmental improvement. ${ }^{30}$

Finally, we note that the main result of the previous section also holds under external increasing returns. A growing economy may initially exhibit declining environmental quality because agents choose not to maintain it. It is straightforward to show that an economy on a sustained growth path will not engage indefinitely in zero maintenance. Hence economies that achieve a sustained growth path in the model will ultimately be characterised by improving environmental quality. This possibility is illustrated in Fig. 5 .

30 The possibility of a low-level equilibrium in this model also bears on the current debate over whether or not economies converge over time. For example, Durlauf and Johnson (1992) argue that the Summers and Heston (I99I) international data set supports the idea that there is local but not global convergence; that is, countries with similar initial conditions converge to the same equilibrium, but countries with different initial conditions do not. 


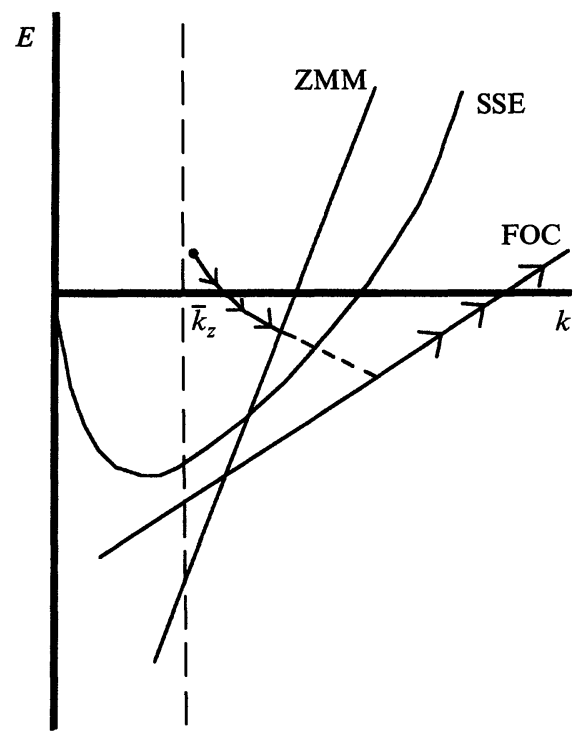

Fig. 5. Initial decline and subsequent improvement in environmental quality.

V. WELFARE ANALYSIS

Since environmental damage may outlive its perpetrators, overlapping generations models provide an appropriate demographic structure for analysis of environmental externalities. The structure complicates the analysis of Pareto-improving policies, since the welfare of multiple generations must be considered. Moreover, intergenerational externalities are intrinsically hard to internalise: those imposing the externalities are not alive at the same time as those who enjoy or suffer the consequences.

We first find the golden-rule allocation by analysing the problem of a social planner who treats all generations symmetrically. The planner solves

subject to

$$
\text { Maximise } U(c, E)
$$

$$
\begin{gathered}
y+(\mathrm{I}-\delta) k=c+m+k \\
y=\psi(k) f(k), \\
b E=\gamma m-\beta c,
\end{gathered}
$$

where (32) and (33) represent economic feasibility and (34) is the steady-state environment equation. Eliminate $m$ and solve for $c$ to obtain

$$
c=\frac{\gamma(y-\delta k)-b E}{\beta+\gamma} .
$$

Equation (35) expresses consumption as a function of $k$ and $E$ in any steady state. Substituting into the objective function, we obtain

$$
\underset{E, k}{\operatorname{maximise}} U\left[\frac{\gamma(y-\delta k)-b E}{\beta+\gamma}, E\right] \text {. }
$$

(C) Royal Economic Society 1994 
The first-order conditions are

$$
\begin{gathered}
U_{1}()\left(\psi f^{\prime}+\psi^{\prime} f-\delta\right)\left(\frac{\gamma}{\beta+\gamma}\right)=0 \\
U_{1}()=\left(\frac{\beta+\gamma}{b}\right) U_{2}() .
\end{gathered}
$$

From $(36)$, the planner sets capital at the level at which net output is maximised: $\psi f^{\prime}+\psi^{\prime} f=\delta .^{31}$ This is essentially the familiar condition for the golden-rule level of capital; in the absence of external increasing returns it reduces to $f^{\prime}=\delta$. From (37), the planner equates the marginal rate of substitution of consumption for maintenance to the marginal rate of transformation. The solution decomposes in this way because the planner can translate any increase in output into increased consumption and maintenance such that environmental quality is constant, unambiguously increasing utility. The planner thus maximises output, and then divides it optimally.

Note that (37) is a dynamic analog of the Samuelson condition for the optimal provision of a public good, where marginal rates of substitution are in this case summed across generations, rather than individuals. Environmental quality is a public good that depreciates at rate $b$, so a one-unit improvement in environmental quality for one generation implies improvements of $(\mathrm{I}-b)$, $(\mathrm{I}-b)^{2},(\mathrm{I}-b)^{3}$, and so on, for subsequent generations. This infinite sum gives rise to the ' $b$ ' in the right-hand-side denominator of (37). Comparing (37) with (7) establishes that the planner internalises the consumption externality (the $\beta / b$ term) and the maintenance externality (the $\mathrm{I} / b$ in the $\gamma / b$ term). We can interpret equation (37) as defining the optimal $E$ for given $k$. It is easily shown that it attains a maximum at the golden rule capital stock, as shown in Fig. 6 .

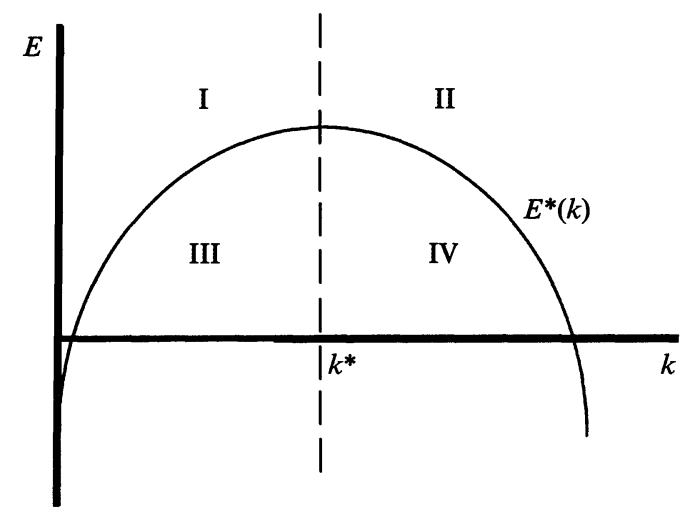

Fig. 6 . The golden rule allocation.

As is well-known, the competitive equilibrium of an overlapping generations model can be dynamically inefficient, in which case all generations would benefit if they accumulated less capital and increased their consumption. Not

${ }^{31}$ Note that if there are sufficiently strong external increasing returns net output might be unbounded.

(C) Royal Economic Society 1994 
surprisingly, such a result carries over to this model whenever $k$ exceeds its golden rule level (regions II and IV). There is an analogous possibility of inefficiency in terms of environmental quality (regions I and II): agents may overmaintain, implying that all generations could be made better off by maintaining less and consuming more. ${ }^{32}$ In region III, simple Paretoimproving policies are not so easily found, but Pareto improvements can still be implemented by a planner who reallocates resources between generations. These results are formalised in Propositions I and 2.

Proposition I. Consider an economy in steady state. (i) If $\left(\psi f^{\prime}-\delta\right)<\frac{b \gamma}{\beta+\gamma}-\mathrm{I}$, there is overmaintenance of the environment. (ii) Overmaintenance is impossible if the economy is dynamically efficient and there are no external increasing returns $(\psi(k)=\mathrm{I}, \forall k)$.

Proof. (i) Overmaintenance of the environment occurs if, at a given steady-state $k$, equilibrium environmental quality is higher than that chosen by the social planner. Suppose not: fix $k$ and let $E^{I}<E^{P}$, where $I$ denotes the individual and $P$ the planner. From equation (35), $c^{I}>c^{P}$. Now

$$
\begin{aligned}
& U_{1}\left(c^{P}, E^{P}\right)>U_{1}\left(c^{I}, E^{P}\right) \geqslant U_{1}\left(c^{I}, E^{I}\right) ; \\
& U_{2}\left(c^{P}, E^{P}\right) \leqslant U_{2}\left(c^{I}, E^{P}\right)<U_{2}\left(c^{I}, E^{I}\right) ;
\end{aligned}
$$

since $U_{12}() \geqslant 0$. From equations $(7)$ and $(37)$ :

$$
\begin{gathered}
\frac{\left(\mathrm{I}+\psi f^{\prime}-\delta\right)}{\gamma}=\frac{U_{2}\left(c^{I}, E^{I}\right)}{U_{1}\left(c^{I}, E^{I}\right)} ; \\
\left(\frac{b}{\beta+\gamma}\right)=\frac{U_{2}\left(c^{P}, E^{P}\right)}{U_{1}\left(c^{P}, E^{P}\right)} .
\end{gathered}
$$

But combining these results with the previous inequalities contradicts the inequality stated in the proposition. Therefore $E^{P}>E^{I}$, as was to be shown. (ii) Since $\psi=$ I and $\psi^{\prime}()=0$, dynamic efficiency implies $f^{\prime}-\delta \geqslant 0$. The result follows from (i) since $b \gamma /(\beta+\gamma)<\mathrm{I}$.

Proposition 2. Pareto-improving policies are generically possible in any equilibrium with positive maintenance or with no external increasing returns.

Proof. For the sake of economy of notation, we suppose that the economy is initially in steady-state equilibrium $\{\bar{k}, \bar{E}, \bar{m}, \bar{c}\}$, although the method of proof is applicable to any equilibrium. Consider the following perturbation. At time $\tau$, change maintenance by a small amount $\Delta$ (not necessarily positive) and let saving be changed by $-\Delta$. Thus, $m_{\tau}=\bar{m}+\Delta ; k_{\tau+1}=\bar{k}-\Delta$. At time $\tau+2$, change maintenance by $-\alpha: m_{\tau+2}=\bar{m}-\alpha$. Feasibility in period $t$ implies

$$
y_{t}+(\mathrm{I}-\delta) k_{t}=c_{t}+m_{t}+k_{t+1} \text {. }
$$

By feasibility, $c_{\tau}$ is unchanged, and so the utility of all generations born up to

32 If the economy is in region I, II or IV, Pareto-improving policies entail transfers from the young to the old. Such Pareto improvements could be supported by social contracts of the type discussed by Kotlikoff $e t$ al. (1988).

(C) Royal Economic Society 1994 
and including $\tau-\mathrm{I}$ is unchanged. To a first-order approximation, the utility of members of generation $\tau$ is also unchanged (by the envelope theorem). By calculating $c_{\tau+2}$ and $E_{\tau+2}$, taking a Taylor series expansion of the utility of generation $\tau+\mathrm{I}$ and using the first-order condition, we obtain the following expression for the change in utility of that generation:

$$
U_{1}()\left\{\alpha-\left[\psi^{\prime} f-(\mathrm{I}-b)\left(\mathrm{I}+\psi f^{\prime}-\delta\right)-(\beta / \gamma)\left(\mathrm{I}+\psi f^{\prime}-\delta\right)^{2}\right] \Delta\right\}
$$

Now choose $\alpha$ such that this expression equals zero, so that, by construction, utility of all generations up to and including $\tau+\mathrm{I}$ is now unchanged. Consumption of all generations including and after $\tau+2$ is also unchanged by construction. It remains to consider environmental quality at $\tau+3$ :

$$
\begin{array}{r}
E_{\tau+3}=\bar{E}+\left[(\mathrm{I}-b)^{2} \gamma+(\mathrm{I}-b)(2 \beta+\gamma)\left(\mathrm{I}+\psi f^{\prime}-\delta\right)\right. \\
\left.+\beta(\mathrm{I}+\beta / \gamma)\left(\mathrm{I}+\psi f^{\prime}-\delta\right)^{2}-\gamma \psi^{\prime} f\right] \Delta .
\end{array}
$$

If the expression in parentheses is positive, then $\Delta>0$ (increased maintenance and reduced consumption) is Pareto-improving. Conversely, if this expression is negative, then $\Delta<0$ is Pareto-improving. Setting $\Delta<0$ is not possible in a zero-maintenance equilibrium. The first three terms in this expression are positive, because increased maintenance and reduced consumption improve environmental quality. The last term captures the externality from capital investment: lower saving at time $\tau$ implies lower output at time $\tau+2$. To complete the proof, note that the effect on $E_{\tau+3}$ is first-order, so we can compensate generations $\tau$ and $\tau+$ I for their second-order losses (by increasing consumption and decreasing maintenance by small amounts in periods $\tau+\mathrm{I}$ and $\tau+2$ ), while still ensuring that environmental quality remains higher at $\tau+3$.

Pareto-improvements are generically possible because there are two conflicting externalities associated with the saving/maintenance decision. Increased saving benefits future generations through the external increasing returns, and hurts future generations through reduced maintenance and greater consumption; higher saving is desirable if the first effect dominates. ${ }^{33}$

\section{GONCLUSION}

The relationship between growth and the quality of the environment is complex. Some elements of environmental quality appear to improve with growth; others worsen; still others exhibit deterioration followed by amelioration. We offer an explanation of these findings in a simple dynamic model in which agents accumulate both capital and environmental quality. Multiple Pareto-ranked steady-state equilibria can arise as a result of the interaction between capital accumulation and environmental quality. Short-lived agents may overinvest in environmental quality in a manner analogous to dynamically

\footnotetext{
33 As noted in the proof, increased saving is not possible in a zero-maintenance equilibrium. We do not emphasise this result since it is almost certainly not robust to a change in the model whereby agents consume in both periods of life.
}

(C) Royal Economic Society I994 
inefficient capital accumulation. Even when the economy is dynamically efficient in terms of capital and the environment, Pareto improvements can be implemented by a long-lived planner.

Our model is stylised and could be extended in many ways. In general, environmental externalities could arise from production or consumption and could affect welfare or productivity. We focus here only on externalities from consumption to utility, but other linkages are worthy of further study. We assumed exogenous pollution and maintenance functions, so agents could not invest in cleaner production technologies or better maintenance technologies. The patterns of pollution and growth observed in the data also suggest that a model with more than one type of environmental externality may be informative. And, while we have identified possible Pareto-improvements, we have said little about either the efficacy or the implementation of different policies. All of these are topics for future research. Finally, we emphasise again that the distinguishing feature of our model is the existence of a long-lived public good. While we have discussed our model in terms of environmental quality, the analysis has more general applicability.

\section{University of Virginia}

\section{Michigan State University}

Date of receipt of final typescript: May 1994

\section{REFERENCES}

Allais, M. (1947). Economie et Intérêt. Paris: Imprimerie Nationale.

Arrow, K. (1962). 'The economic implications of learning by doing.' Review of Economic Studies, vol. 29, pp. I $55^{-73}$.

Azariadis, C. and Drazen, A. (I990). 'Threshold externalities in economic development.' Quarterly Journal of Economics, vol. 105, pp. 501-26.

Baumol, W. and Oates, W. (I988). The Theory of Environmental Policy. Cambridge: Cambridge University Press.

Dasgupta, P. and Heal, G. (1979). Economic Theory and Exhaustible Resources. Cambridge: Cambridge University Press.

Diamond, P. (I965). 'National debt in a neoclassical growth model.' American Economic Review, vol. 55, pp. I $126-50$.

Durlauf, S. and Johnson, P. (1992). 'Local versus global convergence across national economies.' Mimeo, Stanford University.

Grossman, G. and Krueger, A. (I99I). 'Environmental impacts of a North American Free Trade Agreement.' NBER Working Paper No. 3914.

Howarth, R. and Norgaard, R. (I99o). 'Intergenerational resource rights, efficiency, and social optimality.' Land Economics, vol. 66, pp. I-I I.

John, A. and Pecchenino, R. (I993). 'International and intergenerational environmental externalities.' Mimeo, Michigan State University.

John, A., Pecchenino, R., Schimmelpfennig, D. and Schreft, S. (I 994). 'Short-lived agents and the long-lived environment.' forthcoming, Journal of Public Economics.

Jones, L. and Manuelli, R. (1992). 'Finite lifetimes and growth.' Journal of Economic Theory, vol. 58, pp. I 7 I -97 .

Kemp, M. and Long, N. (1980). 'The underexploitation of natural resources: a model with overlapping generations.' In Exhaustible Resources, Optimality and Trade (ed. M. Kemp and N. Long). Amsterdam: North Holland.

Kotlikoff, L., Persson, T. and Svensson, L. (1988). 'Social contracts as assets: a possible solution to the timeconsistency problem.' American Economic Review, vol. 78, pp. 662-77.

Lucas, R. (I988). 'On the mechanics of economic development.' Journal of Monetary Economics, vol. 2 I, pp. 3-42.

(C) Royal Economic Society I994 
Mäler, K.-G. (I993). 'Economic growth and the environment.' Beijer International Institute of Ecological Economics Discussion Paper Series No. 25.

Mourmouras, A. (I99I). 'Competitive equilibria and sustainable growth in a life-cycle model with natural resources.' Scandinavian Journal of Economics, vol. 9i, pp. 585-91.

Romer, P. (1986). 'Increasing returns and long-run growth.' Journal of Political Economy, vol. 94, pp. $1002-37$.

Samuelson, P. (1958). 'An exact consumption-loan model of interest with or without the social contrivance of money.' Journal of Political Economy, vol. 66, pp. 467-82.

Sandler, T. (1982). 'A theory of intergenerational clubs.' Economic Inquiry, vol. 20, pp. I9I-208.

Selden, T. and Song, D. (1992). 'Environmental quality and development: is there a Kuznets curve for air pollution?' Mimeo, Syracuse University.

Solow, R. (1974). 'The economics of resources or the resources of economics.' American Economic Review, vol. 64 , pp. I-14.

Solow, R. (I 986$)$. ' On the intergenerational allocation of natural resources.' Scandinavian Journal of Economics, vol. 88 , pp. $14 \mathrm{I}^{-9}$.

Stokey, N. (1988). 'Learning by doing and the introduction of new goods.' Journal of Political Economy, vol. 96 , pp. $701-17$.

Summers, R. and Heston, A. (I991). 'The Penn world table (mark V): an expanded set of international comparisons, I950-i 988.' Quarterly Journal of Economics, vol. I06, pp. 327-68.

Weil, P. (1989). 'Increasing returns and animal spirits.' American Economic Review, vol. 79, pp. 889-94.

World Bank (1992). World Development Report 1992: Development and the Environment. New York: Oxford University Press.

Young, A. (1928). 'Increasing returns and economic progress.' Economic Journal, vol. 38, pp. 527-42. 
http://www.jstor.org

\title{
LINKED CITATIONS
}

- Page 1 of 4 -

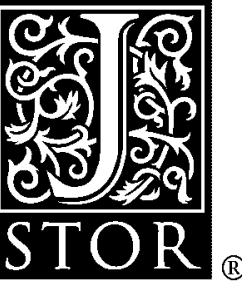

You have printed the following article:

\section{An Overlapping Generations Model of Growth and the Environment}

A. John; R. Pecchenino

The Economic Journal, Vol. 104, No. 427. (Nov., 1994), pp. 1393-1410.

Stable URL:

http://links.jstor.org/sici?sici=0013-0133\%28199411\%29104\%3A427\%3C1393\%3AAOGMOG\%3E2.0.CO\%3B2-Y

This article references the following linked citations. If you are trying to access articles from an off-campus location, you may be required to first logon via your library web site to access JSTOR. Please visit your library's website or contact a librarian to learn about options for remote access to JSTOR.

\section{[Footnotes]}

\author{
${ }^{1}$ Intergenerational Resource Rights, Efficiency, and Social Optimality \\ Richard B. Howarth; Richard B. Norgaard \\ Land Economics, Vol. 66, No. 1. (Feb., 1990), pp. 1-11. \\ Stable URL: \\ http://links.jstor.org/sici?sici=0023-7639\%28199002\%2966\%3A1\%3C1\%3AIRREAS\%3E2.0.CO\%3B2-C

\section{${ }^{9}$ Increasing Returns and Long-Run Growth} \\ Paul M. Romer \\ The Journal of Political Economy, Vol. 94, No. 5. (Oct., 1986), pp. 1002-1037. \\ Stable URL: \\ http://links.jstor.org/sici?sici=0022-3808\%28198610\%2994\%3A5\%3C1002\%3AIRALG\%3E2.0.CO\%3B2-C \\ ${ }^{9}$ Increasing Returns and Animal Spirits \\ Philippe Weil \\ The American Economic Review, Vol. 79, No. 4. (Sep., 1989), pp. 889-894. \\ Stable URL: \\ http://links.jstor.org/sici?sici=0002-8282\%28198909\%2979\%3A4\%3C889\%3AIRAAS\%3E2.0.CO\%3B2-1
}

\author{
${ }^{9}$ The Economic Implications of Learning by Doing \\ Kenneth J. Arrow \\ The Review of Economic Studies, Vol. 29, No. 3. (Jun., 1962), pp. 155-173. \\ Stable URL: \\ http://links.jstor.org/sici?sici=0034-6527\%28196206\%2929\%3A3\%3C155\%3ATEIOLB\%3E2.0.CO\%3B2-\%23
}

NOTE: The reference numbering from the original has been maintained in this citation list. 
http://www.jstor.org

\title{
LINKED CITATIONS
}

- Page 2 of 4 -

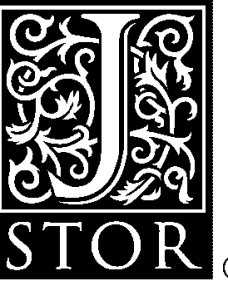

\footnotetext{
${ }^{9}$ Increasing Returns and Economic Progress
}

Allyn A. Young

The Economic Journal, Vol. 38, No. 152. (Dec., 1928), pp. 527-542.

Stable URL:

http://links.jstor.org/sici?sici=0013-0133\%28192812\%2938\%3A152\%3C527\%3AIRAEP\%3E2.0.CO\%3B2-R

\author{
${ }^{10}$ National Debt in a Neoclassical Growth Model \\ Peter A. Diamond \\ The American Economic Review, Vol. 55, No. 5, Part 1. (Dec., 1965), pp. 1126-1150. \\ Stable URL: \\ http://links.jstor.org/sici?sici=0002-8282\%28196512\%2955\%3A5\%3C1126\%3ANDIANG\%3E2.0.CO\%3B2-L
}

\section{${ }^{30}$ The Penn World Table (Mark 5): An Expanded Set of International Comparisons, 1950-1988}

Robert Summers; Alan Heston

The Quarterly Journal of Economics, Vol. 106, No. 2. (May, 1991), pp. 327-368.

Stable URL:

http://links.jstor.org/sici?sici=0033-5533\%28199105\%29106\%3A2\%3C327\%3ATPWT\%285\%3E2.0.CO\%3B2-D

\footnotetext{
${ }^{32}$ Social Contracts as Assets: A Possible Solution to the Time-Consistency Problem Laurence J. Kotlikoff; Torsten Persson; Lars E. O. Svensson

The American Economic Review, Vol. 78, No. 4. (Sep., 1988), pp. 662-677.

Stable URL:

http://links.jstor.org/sici?sici=0002-8282\%28198809\%2978\%3A4\%3C662\%3ASCAAAP\%3E2.0.CO\%3B2-6
}

\section{References}

\author{
The Economic Implications of Learning by Doing \\ Kenneth J. Arrow \\ The Review of Economic Studies, Vol. 29, No. 3. (Jun., 1962), pp. 155-173. \\ Stable URL: \\ http://links.jstor.org/sici?sici=0034-6527\%28196206\%2929\%3A3\%3C155\%3ATEIOLB\%3E2.0.CO\%3B2-\%23
}

NOTE: The reference numbering from the original has been maintained in this citation list. 
http://www.jstor.org

\section{LINKED CITATIONS}

- Page 3 of 4 -

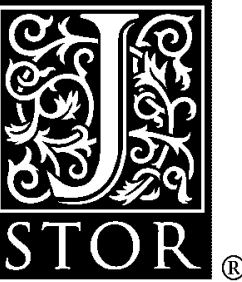

Threshold Externalities in Economic Development

Costas Azariadis; Allan Drazen

The Quarterly Journal of Economics, Vol. 105, No. 2. (May, 1990), pp. 501-526.

Stable URL:

http://links.jstor.org/sici?sici=0033-5533\%28199005\%29105\%3A2\%3C501\%3ATEIED\%3E2.0.CO\%3B2-A

\section{National Debt in a Neoclassical Growth Model}

Peter A. Diamond

The American Economic Review, Vol. 55, No. 5, Part 1. (Dec., 1965), pp. 1126-1150.

Stable URL:

http://links.jstor.org/sici?sici=0002-8282\%28196512\%2955\%3A5\%3C1126\%3ANDIANG\%3E2.0.CO\%3B2-L

Intergenerational Resource Rights, Efficiency, and Social Optimality

Richard B. Howarth; Richard B. Norgaard

Land Economics, Vol. 66, No. 1. (Feb., 1990), pp. 1-11.

Stable URL:

http://links.jstor.org/sici?sici=0023-7639\%28199002\%2966\%3A1\%3C1\%3AIRREAS\%3E2.0.CO\%3B2-C

Social Contracts as Assets: A Possible Solution to the Time-Consistency Problem

Laurence J. Kotlikoff; Torsten Persson; Lars E. O. Svensson

The American Economic Review, Vol. 78, No. 4. (Sep., 1988), pp. 662-677.

Stable URL:

http://links.jstor.org/sici?sici=0002-8282\%28198809\%2978\%3A4\%3C662\%3ASCAAAP\%3E2.0.CO\%3B2-6

\section{Increasing Returns and Long-Run Growth}

Paul M. Romer

The Journal of Political Economy, Vol. 94, No. 5. (Oct., 1986), pp. 1002-1037.

Stable URL:

http://links.jstor.org/sici?sici=0022-3808\%28198610\%2994\%3A5\%3C1002\%3AIRALG\%3E2.0.CO\%3B2-C

An Exact Consumption-Loan Model of Interest with or without the Social Contrivance of Money

Paul A. Samuelson

The Journal of Political Economy, Vol. 66, No. 6. (Dec., 1958), pp. 467-482.

Stable URL:

http://links.jstor.org/sici?sici=0022-3808\%28195812\%2966\%3A6\%3C467\%3AAECMOI\%3E2.0.CO\%3B2-Z

NOTE: The reference numbering from the original has been maintained in this citation list. 
http://www.jstor.org

\section{LINKED CITATIONS \\ - Page 4 of 4 -}

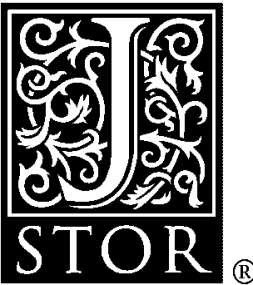

The Economics of Resources or the Resources of Economics

Robert M. Solow

The American Economic Review, Vol. 64, No. 2, Papers and Proceedings of the Eighty-sixth Annual Meeting of the American Economic Association. (May, 1974), pp. 1-14.

Stable URL:

http://links.jstor.org/sici?sici=0002-8282\%28197405\%2964\%3A2\%3C1\%3ATEOROT\%3E2.0.CO\%3B2-4

\section{Learning by Doing and the Introduction of New Goods}

Nancy L. Stokey

The Journal of Political Economy, Vol. 96, No. 4. (Aug., 1988), pp. 701-717.

Stable URL:

http://links.jstor.org/sici?sici=0022-3808\%28198808\%2996\%3A4\%3C701\%3ALBDATI\%3E2.0.CO\%3B2-K

The Penn World Table (Mark 5): An Expanded Set of International Comparisons, 1950-1988

Robert Summers; Alan Heston

The Quarterly Journal of Economics, Vol. 106, No. 2. (May, 1991), pp. 327-368.

Stable URL:

http://links.jstor.org/sici?sici=0033-5533\%28199105\%29106\%3A2\%3C327\%3ATPWT\%285\%3E2.0.CO\%3B2-D

\section{Increasing Returns and Animal Spirits}

Philippe Weil

The American Economic Review, Vol. 79, No. 4. (Sep., 1989), pp. 889-894.

Stable URL:

http://links.jstor.org/sici?sici=0002-8282\%28198909\%2979\%3A4\%3C889\%3AIRAAS\%3E2.0.CO\%3B2-1

\section{Increasing Returns and Economic Progress}

Allyn A. Young

The Economic Journal, Vol. 38, No. 152. (Dec., 1928), pp. 527-542.

Stable URL:

http://links.jstor.org/sici?sici=0013-0133\%28192812\%2938\%3A152\%3C527\%3AIRAEP\%3E2.0.CO\%3B2-R

NOTE: The reference numbering from the original has been maintained in this citation list. 